\title{
UNIQUE APPROACH TO CONTROL SPEECH, SENSORY AND MOTOR NEURONAL DisORDER Through Natural Language Processing AND Cognitive Development: A REVIEW
}

\author{
Vinay Kumar Pandey, Angana Saikia, Sudip Paul \\ Department of Biomedical Engineering, North Eastern Hill University Shillong, India.
}

\begin{abstract}
Cognitive science is an effective approach for bringing mentally retarded person in to live normal way of life. Overcoming cognitive disorders involves initiating the growth of natural thinking. A large population in this world is suffering from cognitive disorders either less or more. Cognitive disorders can be of due to developmental issue or acquired from illness/accidental. Cognitive development can be achieved by natural therapy by stimulation of specific neuronal network which are involved in cognition. Brain based skills that involved in this make a complex task into simpler task. These skills show how we learn, how we think, how we remember and most importantly how we respond to a specific situation. For instance, perception is the recognition and interpretation of opinion or in what way you are taking problem and solving in which way because a single problem solved by different persons in different way of thinking. In such a situation it is very important to develop basic cognitive abilities in infants in its early developmental stage by providing necessary therapy in childhood. To bring this reality in society here an attempt will be made to design a virtual therapy device that will give the necessary exercises to the infants for growth of proper neural network i.e. brain development to overcome mental retardation and cognitive disorder.
\end{abstract}

\section{KEYWORDS}

Cognitive Disorders and Therapy, Neuronal Network, Motor Neurons.

\section{INTRODUCTION}

The study of neurophysiology in the field of cognitive science domain has been intense since last few decades having various strategies but it has attained a limited success [1]. Because of the fact it has a wide variety of difficulties which is difficult to solve due to complexity and diversity of the knowledge and problems confronted. To resolve these problems one common approach is connectionist approach in which neuronal network adjust them with respect to threshold value and connection weights. Natural cognitive development process plays a key role in growing children and adults [2]. It will create a common way of general thinking, memory and situation reaction abilities. This can be achieved by appointing a specific cognitive therapist teacher in each and every school so that necessary exercise for brain development should be provided to the infants during school hours as course curriculum. This is a new initiative that should be started by the government to overcome these disorders. Implementing speech and cognitive therapist in school settings not only helping developing cognition but also helps in enhancing the academic 
International Journal on Natural Language Computing (IJNLC) Vol.7, No.5, October 2018

performance. This study is based upon the application of early childhood therapy in improving the cognitive and language processing ability of infants during school days as a course curriculum. There are an increasing number of mentally retarded or parallelized patients from infants and adults who are unable to work or responding basic fields of life [3]. The developmental disabilities like mental retardation, cerebral palsy, oral motor disorder, sensory disorders, communication disorders, hyperactive disorder, learning disorder, emotional disorder and cognitive disorder accounts approximately $15 \%$ of child population [4].Among these cerebral palsy and cognitive disorders are more common and they needing long term care for treatment. Indian government is has been taken attention in this field from last few years by establishing composite regional centers in regions like- Ranchi, Lucknow, Jaipur, Chennai and more. The ministry of social justice and empowerment has opened some institutions like NIEPMD, Chennai and NISH Thiruvananthapuram to work in this field. There is an increasing pressure on these institutes to provide effective treatment. Because this needs long term care so the cost of treatment also increases from parent and institutional point of view [5]. So, it will be a better option to provide then either a virtual environment that will provide necessary therapy to the child in home premises so that the cost of treatment and effectiveness can be improved.

\section{SYMPTOMS AND CAUSES SPEECH LANGUAGE AND COGNITIVE DiSORDER}

Children having speech language and cognitive disorder are having one are more symptoms depending on severity of the problem. These problems can be of understanding, expression or issue with spoken and written interpersonal communication that are known as the visible symptoms of speech language disorder. Language impairment may occur with other developmental disorder and acquired accidental disabilities like aphasia, apraxia, dysarthria etc. Developmental speech and language disorder is most commonly seen in preschool children and infants. This affects learning ability which is caused by brain functional activity as a result child face trouble in producing speech, language and communicative skills. Early speech and language problems are one of the early symptoms of the learning disability that has been found with hearing loss and delayed speech. Premature birth, intellectual disability, developmental delays, cerebral palsy, muscular dystrophy and traumatic brain injury can affect normal speech and cognition of child. Neurological problems associated with cognitive disorders are seizure disorder $33 \%-50 \%$, mental retardation 50\%-70\%, learning disorder 60\%-70\%, dysarthria 50\%, behavioral problems, speech, swallow and breathing disorders and sleep disturbances [6]. The first and foremost sign of cognitive disability is developmental delay i.e. language, walking and self-care skills. After some time when child starts his school at that time he might have trouble in reading and doing mathematics.

\section{Cognitive Development}

Children in age group of 6 years to 12 years normally start thinking in solid and concrete manner in order to combine words i.e. how to speak in a meaningful way by separating and transforming object and actions. This cognition process grows with time and experience. Cognitive development is stage based development that continues to grow from early childhood to adulthood. Theses stages are defined as neural architecture or cognitive structure in which child is able to respond to different types of stimuli from environment. Cognitive structure describes the classes of children activities psychological as well as behavioral. The various theories of cognitive development say that these skills grow through a series of stages which can be differentiated qualitatively [7]. The developmental process depends upon various parameters like 
International Journal on Natural Language Computing (IJNLC) Vol.7, No.5, October 2018

nutrition, environment and early childhood care because child is very sensitive to the environment and tries to cop up with the present environment. In this way he develops new infrastructure and organization of neural network. In the sensory motor stage the child behavior is not thoughtful that means he does not think what he is doing or going to do according to situation. Adulthood and adolescence stage child will be able to think and respond accordingly.

\section{Utility of Modern Technology in Enhancing Cognitive DEVELOPMENT}

Modern day's children's growth of skills are influenced by technologically developed electronic devices environment. These devices plays important role in day to day life and may affect natural consequence. They are interested in playing games either with devices or with same age group children but present scenario restrict them to play within home premises as the parents don't want to send him outside. By utilizing these favorable conditions in useful means we can protect our child from speech language and cognitive disorder. With the increasing number of mobile and other hand held device users a new solution of physical therapy are being sought in the field of therapy [8]. This can be done by using these devices to provide therapy to the child in a reliable and cost effective manner. Android and ios apps will be the best platform as most of the people are having mobile phone so mobile health solution is the best candidate for this purpose. In this review we identified the android platform have suitable potential for therapeutic application.

\section{Proposed features Of Mobile Apps Which Will Support COGNITIVE THERAPY}

Effectiveness and acceptability is the key of this research. Mobile apps that are being developed will support computer based therapy or mobile based therapy with encompassing the barriers of the clinical therapy [9]. The device should be able to provide the central goal of the therapy, acceptable to both therapist and patient, appropriate to sociocultural context [10], practiced in small sessions to improve skills, doable, small in size, suitable to objective, include demo videos along with audio and text instructions, include backup of previous sessions, produce report of each session including time duration, whole day summary report of all sessions. In addition to that it should have provided reward points after successful completion of each session. With all these we calculated the minimum features of the app are:-

1. Compatible to therapy

2. Promote learning and other skills

3. Guiding therapy or demo therapy

4. Building connections

5. Encourage completion

6. Affordable to all

7. Population specific 
International Journal on Natural Language Computing (IJNLC) Vol.7, No.5, October 2018

\subsection{COMPATIBLE TO THERAPY}

Any Therapeutic intervention should have to meet central goal of the therapy. Mobile apps have to give useful content which are compatible to the therapy for which they are designed. There are different types of therapy that can be accessed at home which are dependent on the nature of disorder is being treated, target and stage of disorder. These records can be used in other treatment like, oral motor, anxiety and depression. This module will provide treatments to cognitive disorder, and other motor neuronal disorders more or less.

\subsection{PROMOTE LEARNING AND OTHER SKILLS}

Cognitive development via therapy takes time and effort to grow normal thinking ability. If patient or child feels any difficulty in or any sense of inconvenience in doing exercise then he will not complete the session resulting a low efficiency of app or device. Therefore task should be simple, attractive and short in duration and having some motivational rewards. Many apps are having ability to send the auto generated report to the clinician that will be the extra feature of the apps/device.

\subsection{GUIDING ThERAPY OR DEMO THERAPY}

Like a therapist the apps will also play an important role in guiding, motivating and instructions to the patient before starting of therapy as a demo session. If we will not provide proper instructions then the patient don't know what to do and how to do that will influence the rationale of the apps. While giving demo session we should be always careful so that the patient should not feel bored. Individuals using internet feedback based therapy that have shown good response in treatments of post-traumatic stress disorder [11], obsessive compulsive disorder [12], chronic pain [13], depression [14], and stress mitigation [15].

\subsection{BUILding CONNECTIONS}

The apps should be able to interact with similar programs and devices. The team of device/apps, therapist/clinic and patient make a strong prediction of future needs and requirement of the treatment. Till date there is no adverse effect of app/device based therapy [16, 17]. More significantly the greatest advantage of this is that it can be updated from anywhere and can be added more features. This can be shared to the suffering peoples via using app share or any other sharing tools.

\subsection{EnCOURAGE COMPLETION}

All user needs immediate effect that will attract him to do otherwise they don't want to do or discourage him. In this scenario, it is important for both mobile app and clinician to encourage him to complete the session. During session app will show achieved this level, first round completed and graphical feedback to motivate him $[18,19]$ so that they are curious to get next level of task. 
International Journal on Natural Language Computing (IJNLC) Vol.7, No.5, October 2018

\subsection{AfFordable To All}

The mobile app or device should be affordable to all i.e. it should have low cost or freely available to all without any cost. If we are charging for that then economically backward class of society will be unable to get these facilities that will be the barrier in popularity of this mobile app.

\subsection{Population Specific}

This app is exclusively designed for growing child of 3 years to 8 years of age group taking into the account of specific characteristics of the target as cognitive development. A specific app designed specifically for stress management by Chinese international students which incorporates social and cultural features in gaming format [20]. In which gaming activity is applied for the treatment of breathing problems with the concept of natural energy. Another gaming device focusing on autism spectrum disorder uses multi touch approach to teach concepts of conversation and social collaboration. In all these touch screen based games offer stimulated activities to the children who have difficulties in peer engagement can collaborate to accomplish tasks [21]. Children involved in this treatment process have shown good improvement in social collaboration and better understanding of things.

\section{LiMitATIONS}

All the app features are taken on the basis of current days problems that are faced by the patient during therapy. As the technological advancement the features of the app may change according to the need and requirement of therapy exercises. These apps can be made more powerful by implementing the concept of artificial intelligence and emotional sensing.

\section{CONCLUSION}

This present study is based on idea and opinion of various parents of children, researchers, clinicians, doctors, and which is supported by extensive literature review. The basic features of the mobile app listed in this paper are the key characteristics of therapy related apps that are supposed to be used in treatment of cognitive development and neuronal development. The development of such type of apps are under process that will take some time to get available in the market randomized testing and impact of therapy by using this app will be done at later stage. Some health related therapy apps and device are now available in developed countries that motivated us to work in this field that will be directly useful for society and disabled child.

\section{REFERENCES}

[1] Gardner H. E.,(2008). “The mind's new science: A history of the cognitive revolution”,Basic books.

[2] Blair C.,(2002). "School readiness: Integrating cognition and emotion in a neurobiological conceptualization of children's functioning at school entry", American psychologist, Vol. 57, No. 2, pp111.

[3] Byrnes J. P., Nathan A. F.,(1998). "The educational relevance of research in cognitive neuroscience", Educational Psychology Review, Vol. 10, No. 3,pp297-342. 
International Journal on Natural Language Computing (IJNLC) Vol.7, No.5, October 2018

[4] Schmahmann J. D.,(2004). "Disorders of the cerebellum: ataxia, dysmetria of thought, and the cerebellar cognitive affective syndrome", The Journal of neuropsychiatry and clinical neurosciences, Vol. 16, No. 3, pp367-378.

[5] Sabaté, Eduardo,(2003). "Adherence to long-term therapies: evidence for action", World Health Organization.

[6] Filipek P. A., Accardo P. J., Ashwal S., Baranek G. T., Cook E. H., Dawson G., Gordon B., Gravel J. S., Johnson C. P., Kallen R. J., Levy S. E., Minshew N. J., Ozonoff S., Prozant B. M., Rapin I., Rogers S. J., Stone W. 1., Teplin S. W., Tuchman R. F., Volkmar F. R.,(2000). "Practice parameter: Screening and diagnosis of autism Report of the Quality Standards Subcommittee of the American Academy of Neurology and the Child Neurology Society", Neurology, Vol. 55, No. 4,pp468-479.

[7] Keil F. C.,(1992). "Concepts, kinds, and cognitivedevelopment", MIT Press.

[8] Price M., Yuen E. K., Goetter E. M., Herbert J. D., Foreman E. M., Acierno R., Riggiero K. J.,(2014). "mHealth: a mechanism to deliver more accessible, more effective mental health care", Clinical psychology \& psychotherapy, Vol. 21, No. 5,pp427-436.

[9] Shen N., Levitan M. J., Johnson A., Bender J. L., Hamilton-Page M., Jadad A. R., Wiljer D.,(2015). "Finding a depression app: a review and content analysis of the depression app marketplace", JMIR mHealth and uHealth,Vol. 3, No. 1.

[10] Tompkins M. A.,(2002). "Guidelines for enhancing homework compliance", Journal of clinical psychology, Vol. 58, No. 5,pp565-576.

[11] Pallavicini F., Repetto C., Gorini A., Riva G.,(2009). "Biofeedback, virtual reality and mobile phones in the treatment of Generalized Anxiety Disorder (GAD): A phase-2 controlled clinical trial", Journal of Cyber Therapy and Rehabilitation,Vol. 2, No. 4, pp315-327.

[12] Whiteside S. P., ale C. M., Douglas K. V., Tiede M. S., Dammann J. E.,(2014). Case examples of enhancing pediatric OCD treatment with a smartphone application, Clinical Case Studies, Vol. 13, No. 1, pp80-94.

[13] Kristjansdottir O. B., Fros E. A., Eide E., Finset A., Stensrud T. L., Dulmen S. V., Wigers S. H., Eide H.,(2013). "A smartphone-based intervention with diaries and therapist-feedback to reduce catastrophizing and increase functioning in women with chronic widespread pain: randomized controlled trial", Journal of Medical Internet ResearchVol. 15, No. 1.

[14] Wiederhold B. K., Boyd C., Sulea C., Gaggioli A., Riva G.,(2014). "Marketing analysis of a positive technology app for the self-management of psychological stress", Stud Health Technol InformVol. 199,pp83-87.

[15] Merry S. N., Stasiak K., Shepherd M.,(2012). "The effectiveness of SPARX, a computerized selfhelp intervention for adolescents seeking help for depression: randomized controlled non-inferiority trial”, BMJVol. 344, pp2598.

[16] Morris, M. E., Kathawala Q., Leen T. K., Gorenstein E. E., Guilak F., Labhard M., Deeleeuw W.,(2010). "Mobile therapy: case study evaluations of a cell phone application for emotional selfawareness", Journal of medical Internet research,Vol. 12, No. 2.

[17] Vogel P. A., Launes G., Moen E. M., Solem S., Hansen B., Haland A. T., Himle J. A.,(2012). "Videoconference and cell phone-based cognitive behavioral therapy of obsessive-compulsive disorder: a case series", Journal of anxiety disorders,Vol. 26, No. 1,pp158-164.

[18] Harrison V., Proudfoot J., Wee P. P., Parker G., Pavlovik D. H., Manicavasagar V.,(2011). "Mobile mental health: review of the emerging field and proof of concept study", Journal of mental healthVol. 20, No. 6,pp509-524.

[19] Mattila E., Korhonen I., Salminen J. H., Koskinen E., Sarela A., Parkka J., Lappalainen R.,(2010). "Empowering citizens for well-being and chronic disease management with wellness diary",IEEE Transactions on Information Technology in Biomedicine, Vol. 14, No. 2,pp456-463.

[20] Lee, Matthew D., Xiao Kang, and Nancy Hanrahan.,(2014). "Addressing cultural contexts in the management of stress via narrative and mobile technology", Stud Health Technol InformVol. 199, pp173-177.

[21] Kiluk, Brian D., Serafini K., Frankforter T., Nich C., Carroll K. M.,(2014). "Only connect: the working alliance in computer-based cognitive behavioral therapy”, Behaviour research and therapy, Vol. 63,pp139-146. 
International Journal on Natural Language Computing (IJNLC) Vol.7, No.5, October 2018

\section{AUTHORS}

Mr. Vinay Kumar Pandey is currently working as Ph.D Research Scholar in Department of Biomedical Engineering, North Eastern Hill University, Shillong, Meghalaya India. He completed his maters in VLSI from North Eastern Regional Institute of Science And Technology, Nirjuli, Arunachal Pradesh, and graduated in electronics and communication engineering from Gautum Buddha Technical University Lucknow. The paper entitled "Unique Approach to Control Speech, Sensory and Motor Neuronal Disorder through Natural Language Processing and Cognitive Development: A Review".This paper is review of differently abled children with speech language and cognitive problem. I am grateful to my $\mathrm{PhD}$ supervisor Dr. Sudip Paul for inspiring me to do the research in this field.

Angana Saikia: She is currently pursuing her $\mathrm{PhD}$ in the Department of Biomedical Engineering, NEHU, Shillong. Previously she was working as a Senior Research Fellow (SRF) Department of Biomedical Engineering, NEHU, Shillong. She completed her B.E in Applied Electronics and Instrumentation from Guwahati University, Assam, in 2011 and her M-Tech in Bioelectronics from Tezpur Central University, Assam, India in 2014. Presently she is pursuing her $\mathrm{PhD}$ from Department of Biomedical Engineering, NEHU, Shillong.

Dr. Sudip Paul: He is currently working as Assistant Professor in the Department of Biomedical Engineering, NEHU, Shillong. He completed his BTech in Biomedical Engineering from West Bengal University of Technology, India in 2007 and M-Tech in Biomedical Engineering from Banaras Hindu University, India in 2009. He completed his $\mathrm{PhD}$ from IIT (BHU). He has several research papers in reputed journals in the field of Electrophysiology, Biomedical Instrumentation, Biomedical Signal Processing, Artificial Organ and Rehabilitation System
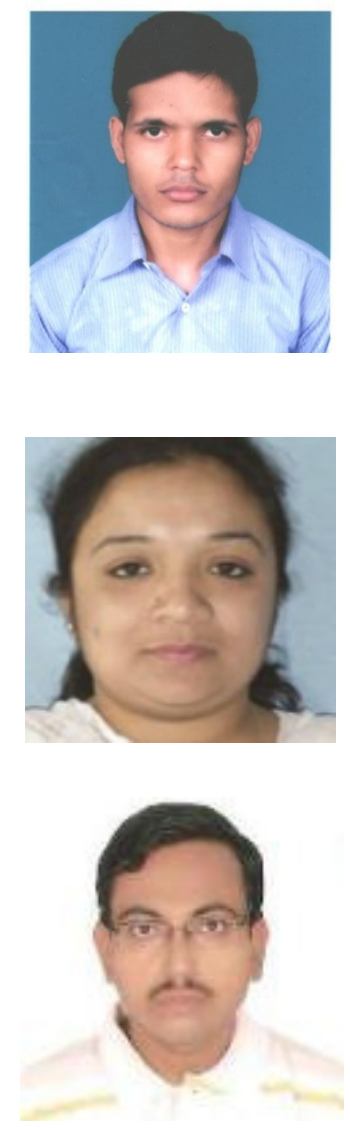